\title{
Prognostic Value of Baseline High-Sensitivity (-Reactive Protein in Patients Undergoing Replacement Arthroplasty
}

\author{
Ghosh S, ${ }^{1}$ Paul S, ${ }^{2}$ Bhattacharjee DP, ${ }^{3}$ Ghosh $\mathrm{P}^{4}{ }^{4}$ Chatterjee $\mathrm{N}^{5}$ \\ 'Department of Orthopaedics, National Medical College, Kolkata, India, ${ }^{2}$ Department of Pharmacology, Medical College, \\ Kolkata, India, ${ }^{3}$ Department of Anesthesiology, National Medical College, Kolkata, India, ${ }^{4}$ Department of Community Medicine, \\ Medical College, Kolkata, India, ${ }^{5}$ Calcutta Medical Research Institute, Kolkata, India
}

\section{ABSTRACT}

Introduction: A prospective hospital based blinded study was carried out in an orthopedics department in a medical college hospital of Kolkata, West Bengal, India, with the objective of assessing the role of pre-operative high-sensitivity C-reactive protein (hsCRP) level in predicting postoperative complications in replacement arthroplasty.

Methods: One hundred and twenty one study subjects were selected. The blood collected in preoperative, perioperative and postoperative states were stored and finally analyzed after the data collection was over after the stipulated follow-up time of post operative Day-14. The patients were divided into two groups according to baseline hsCRP level $<3 \mathrm{mg} / \mathrm{dl}$ and $>3 \mathrm{mg} / \mathrm{dl}$. The other preoperative parameters measured were found to be statistically comparable.

Results: Among important findings, operative time was significantly higher in the group with hsCRP $>3 \mathrm{mg} / \mathrm{dl}$, postoperative complication rate was also significantly more in that group. Postoperative complication in Day-7 though quite high among both the groups ( $45 \%$ and $50.9 \%$ ), the difference was not statistically significant. Comparison of hsCRP levels at baseline, perioperative, postoperative D7 and D14 also showed no significant changes.

Conclusions: We concluded that high hsCRP level( $>3 \mathrm{mg} / \mathrm{dl})$, in patients with apparently no other risk factors may be at higher risk of developing complications after post operative D14 of replacement arthroplasty and operative time also significantly increases with high baseline hsCRP level.

Key Words: postoperative morbidity, reactive protein, replacement arthroplasty

\section{INTRODUCTION}

High sensitivity $\mathrm{C}$ reactive protein (hsCRP) has been considered as an important predictor of cardiovascular risk. It's level is consistent across gender and ethnic groups in the population. ${ }^{1}$ Many studies shows that increased CRP level significantly predicts occurrence of future myocardial infarction, stroke, cardiovascular death and peripheral arterial disease. There is a linear 'doseresponse' association between CRP and subsequent vascular events, which are independent of the traditional risk factors (age, smoking, hypertension, diabetes and dyslipidaemia) evaluated in daily practice. ${ }^{2} A$ three fold higher incidence of cardiovascular disease is found in

\author{
Correspondence: \\ Dr. Suhrita Paul \\ FE-149, Sector-III \\ Salt Lake City \\ Kolkata - 700106 \\ West Bengal, India. \\ Email: drsuhritapaul@yahoo.co.in \\ Phone: +91-33-23217601
}


persons having CRP $>3 \mathrm{mg} / \mathrm{dl}$ when compared to those with $<3 \mathrm{mg} / \mathrm{dl}$.CRP levels are also inversely proportional to $\mathrm{VO} 2 \mathrm{max}$, an important marker of cardio respiratory fitness. ${ }^{3,4}$ Impaired cardio respiratory reserve is strongly associated with poor peri-operative outcome. ${ }^{5}$ The present study aims to find out whether higher levels of pre operative hsCRP is associated with increased perioperative morbidity and mortality in patients undergoing elective, intermediate risk replacement arthroplasty.

\section{METHODS}

A prospective cross-sectional study was conducted in which pre and post operative (baseline, Day-7 and Day- 14) serum hsCRP level has been estimated in all the subjects in the departments of Orthopedics and Anesthesiology of Calcutta National Medical College and Hospitals in collaboration with departments of Pharmacology and Community Medicine, Medical College, Kolkata West Bengal, India from December, 2007- May 2008. Due permission of the Institutional Ethical Committee of Calcutta National Medical College was obtained. Study subjects were enrolled from the patients presenting for elective joint replacement surgery including revision procedures (Total Hip Replacement, Total Knee Replacement and hemi-arthroplasty) in both outpatients' department and inpatients' wards of the Department of Orthopaedics, Calcutta National Medical College after they fulfilled the inclusion and exclusion criteria laid down for the study. Written informed consent was duly obtained from all the participants in their own language.

The patient with either sex, requiring elective joint replacement surgery, revision procedures (Total Hip Replacement, Total Knee Replacement and hemiarthroplasty), fit for major elective surgery as opined by orthopaedician and anesthesiologist and Willingness to give written informed consent for the study procedures were included in the study. The patients with high cardiac risk factors (BP> 160/110 mm of Hg; Grade III, IV angina; uncontrolled heart failure etc.), significant renal impairment (creatinine clearance $<30 \mathrm{ml} / \mathrm{min}$ ), significant hepatic impairment (ALT>200 $\mu \mathrm{g} / \mathrm{dl}$; Prothrombin Time $>15$ seconds), clinically significant physical and mental abnormalities were excluded.

All the patients satisfying the selection criteria were recruited for the study during these six months and after five patients were excluded due to exclusion criteria, finally 121 patients became the study subjects.

Brief history of the subjects was taken and relevant general examinations; laboratory reports of haemoglobin, urine for albumin were recorded. Peripheral venous blood samples were drawn from all patients via a forearm vein in the pre-admission clinic, a mean (SD) of 12 (7) days prior to surgery. Samples were processed immediately, coded and stored at $-800 \mathrm{C}$ until blinded, independent analysis after all clinical data collection had finished. Serum hsCRP level was measured using immunoturbimetric method. The collected blood samples were finally analyzed at the end of study to avoid bias. Preoperative, perioperative and two post operative (day 7 and 14) were collected from the patients.

After analysis of hsCRP level, patients were divided into hsCRP groups low $(<3 \mathrm{mg} / \mathrm{dl})$ and high $(>3 \mathrm{mg} /$ dl) according to the Centre for Disease Control Classification. ${ }^{6}$

Surgery was done under general or regional (epidural or spinal) anesthesia. Assessment of total blood loss done by measuring peri-operative and post- operative drain collection and blood transfusion was done accordingly to compensate the loss. Peri-operative cardiovascular risk index was calculated according to American College of Cardiology guideline ${ }^{7}$ by weighting low $(x 1)$ and intermediate factors $(x 2)$ : No patients had high risk factors.

Evidence based peri-operative factors associated with peri-operative morbidity like body mass index, ${ }^{8}$ operative time, ${ }^{9}$ post-operative haematocrit, ${ }^{10}$ immediate post operative temperature, ${ }^{11}$ were also noted prospectively. Post-operative morbidity (POM) was assessed using a validated system. ${ }^{12}$ Various parameters were tested among the two groups for statistically significant differences. Unpaired ' $\mathrm{t}$ ' test and chi square tests were used as indicated and $\mathrm{P}<0.05$ was considered to be significant.

\section{RESULTS}

Preoperative characteristics of subjects grouped according to hsCRP level $<$ or $>3 \mathrm{mg} / \mathrm{dl}$ (Table 1 ). Comparison of preoperative medication among the study subjects grouped according to hsCRP level $<$ or $>3 \mathrm{mg}$ /dl was done in the cardiac medication status (Table 2). Out of the total 121 patients 60 preoperative samples showed baseline hsCRP level $<3 \mathrm{mg} / \mathrm{dl}$ (mean-1.76) and rest 61 had hsCRP level $>3 \mathrm{mg} / \mathrm{dl}$ (mean-10.5). They were grouped in two different categories and further analysis was done based on this classification. Henceforth, the group with hsCRP $<3 \mathrm{mg} / \mathrm{dl}$ will be referred to as first group and the group with hsCRP $>3 \mathrm{mg} / \mathrm{dl}$ will be referred to as second group. Both the groups showed some similarity in characteristics i.e. male predominance $(60 \%$ and $62.3 \%)$, comparable mean BMI (22.3 and 25.3, P>0.05), a good proportion of smokers $(45 \%$ and $54.1 \%)$ and hypertensive $(51.7 \%$ and $59.02 \%)$. Other co-morbid conditions like diabetes mellitus $(11.7 \%$ and $14.8 \%)$ and chronic obstructive airway diseases $(10 \%$ and $14.8 \%)$ were also comparable in number. 
Intake of cardiac medications was also noted and it showed that majority of the patients in both the groups were already under therapy. First group with hsCRP $<3 \mathrm{mg} / \mathrm{dl}$ had $53(88.3 \%)$ and the other group had $51(83.6 \%)$ patients with cardiac medication. The difference was not statistically significant. Aspirin was the commonest drug in both the groups $137.7 \%$ and $54.1 \%)$, followed by ACE inhibitors $121.7 \%$ and $32.8 \%)$. In first group next commonly used drug was steroids $(20 \%)$ while in the other it was beta blockers (29.5\%). However when we analyzed the medication use pattern in two groups the difference was not statistically significant.

In a group with hsCRP $<3 \mathrm{mg} / \mathrm{dl}$, equal number of patients underwent operation with general and regional anesthesia. In the other group majority had regional anaesthesia (62.3\%) (Table 3). Operative time was significantly higher in case of patients with hsCRP $>3 \mathrm{mg}$ $/$ dl $1107.3 \mathrm{~min}$. compared to $88.5 \mathrm{~min}$ in other group, $\mathrm{P}<0.05$ value-0.0001). Other parameters measured though dissimilar, never were found to be statistically different.

In the first $45 \%(27 / 60)$ patients were reported to have some complication at postoperative day7 (D7), while the number was higher in second group (50.9\%-31/61). The difference was however not statistically significant (Table 4, 5).

GI disorders (26.7\% and 29.5\%), infection $(13.3 \%$ and $19.7 \%)$, cardiac disorder $(11.7 \%$ and $14.8 \%)$ and wound dehiscence $(3.3 \%$ and $6.6 \%)$ were common complication noticed. The differences were not statistically significant.

At post-operative day 14 (D14), number of patients with complication, were greatly reduced $(2 / 60-3.3 \%$ in first group and $10 / 61-16.4 \%$ in second group). The difference was statistically significant. Infection was the commonest $(3.3 \%$ and $11.5 \%)$ complication, followed by $\mathrm{Gl}$ disorders (3.3\% and $4.9 \%$ ) and cardiac complication $(1.7 \%$ and $3.3 \%)$ other disorders noted were neurological problem (one in the first group) and renal impairment (one in the second group)

\section{DISCUSSION}

HsCRP has established itself as a strong predictor of cardiovascular pathology in general non surgical population. Our results from a group of surgical patients at risk of peri operative complications and cardiovascular dysfunction are consistent with these reports. Similar results have been published which highlights the potential importance of preoperative hsCRP in predicting outcome in esophageal resection ${ }^{13}$ and vascular surgery. ${ }^{14}$ The present study aims to find out whether higher levels of pre operative hsCRP is associated with increased peri and post operative morbidity in patients undergoing elective, intermediate risk replacement arthroplasty. The results reveal that hsCRP is definitely an important predictor for post operative complications at D14, but evidence is not enough for its relevance in predicting earlier complications.

Some investigators speculated that very high hsCRP $>10 \mathrm{mg} / \mathrm{dl}$ could be due to acute phase response and might give false positive results, later data showed this to be unlikely. ${ }^{1}$ Orthopaedic patients with chronic, high grade inflammation having persistent high hsCRP $>10$ $\mathrm{mg} / \mathrm{dl}$ are at higher risk. Further, the preoperative CRP levels in patients undergoing revision procedures in our study were not disproportionately distributed in the higher CRP group which matches results of previous reports. ${ }^{15}$

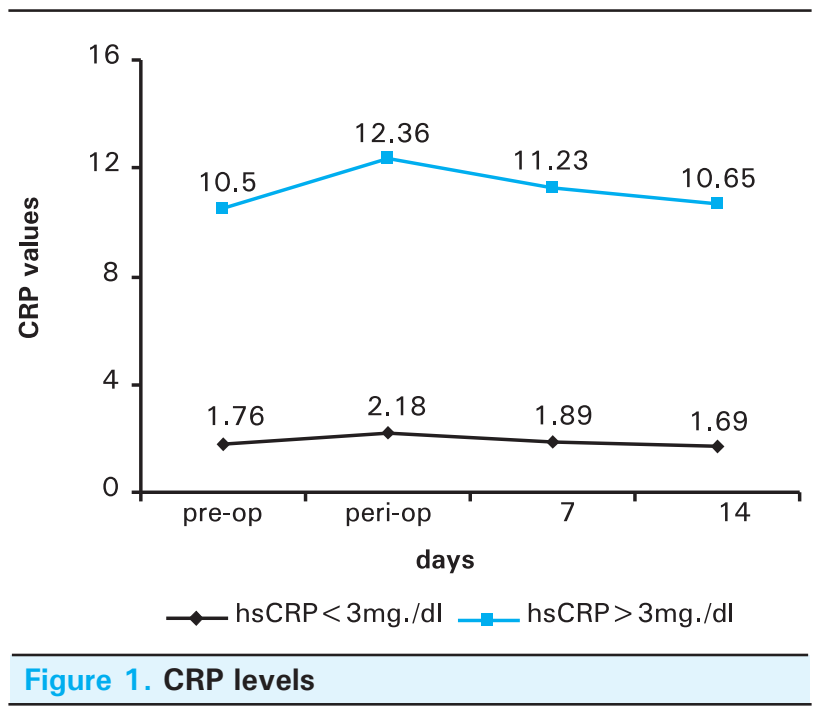

Perioperative outcome is strongly associated with cardio respiratory fitness which can be determined by cardiovascular exercise testing and myocardial ischaemia arising out of it which can predict complications in higher risk surgical patients. ${ }^{5}$ Various studies substantiate the transient increased risk of myocardial infarction after infection. ${ }^{16}$ Again, chronic inflammatory conditions and autoimmune diseases like systemic lupus erythematosus and rheumatoid arthritis are at increased risk of cardiovascular complications. ${ }^{17}$ There is steady association of hsCRP and cardiovascular complications in different patient groups, ${ }^{3,4}$ so estimation of hsCRP may be a useful screening tool to foresee perioperative risks, period of hospitalization and potential costs.

Line diagram comparing CRP levels show that there is no significant change in baseline, seventh and fourteenth postoperative day. The samples were collected within 23 weeks of operation, a time span over which majority of reports suggest hsCRP is unlikely to change. ${ }^{18}$ However regardless of fluctuations in hsCRP levels, several studies emphasize that intermittent, chronic and acute inflammation may all be associated with cardiovascular dysfunction. 
Ghosh et al. Prognostic Value of Baseline High-Sensitivity C-Reactive Protein in Patients ...

Table 1. Preoperative characteristics of subjects grouped according to hsCRP level $<$ or $>3 \mathrm{mg} / \mathrm{dl}$

\begin{tabular}{lccc}
\hline Characteristics & hsCRP $<3 \mathbf{m g . / d l}(\mathbf{n}=\mathbf{6 0})$ & hsCRP $>$ 3mg./dl (n=61) & P-value \\
\hline hsCRP level(mg/dl) & $1.76(1.6-2.0)$ & $10.5(7.4-13.6)$ & $<0.0001$ \\
Age (completed yrs.) & $60(55-72)$ & $61(60-73)$ & 0.455 \\
Male: Female & $36: 24(60 \%: 40 \%)$ & $38: 23(62.3 \%: 37.7 \%)$ & 0.796 \\
BMI (kg/mt2) & $22.3(+5.68)$ & $25.3(+6.01)$ & 0.062 \\
Cardiac history+ & $12(20 \%)$ & $15(24.6 \%)$ & 0.544 \\
Smoker & $27(45 \%)$ & $33(54.1 \%)$ & 0.317 \\
Diabetes mellitus & $7(11.7 \%)$ & $9(14.8 \%)$ & 0.616 \\
Hypertension & $31(51.7 \%)$ & $36(59.02 \%)$ & 0.416 \\
COPD & $6(10 \%)$ & $9(14.8 \%)$ & 0.427 \\
\hline
\end{tabular}

$\mathrm{BMI}=$ Body Mass Index, COPD = Chronic Obstructive Pulmonary Diseases

Table 2. Comparison of preoperative medication among the study subjects grouped according to hsCRP level $<$ or $>$ $3 \mathrm{mg} / \mathrm{dl}$

\begin{tabular}{lccc}
\hline Characteristics & hsCRP $<3 \mathbf{m g . / d l}(\mathbf{n}=\mathbf{6 0})$ & hsCRP $>\mathbf{3 m g . / d l}(\mathbf{n}=\mathbf{6 1})$ & $\mathbf{P}$-value \\
\hline Cardiac medication & $53(88.33 \%)$ & $51(83.6 \%)$ & 0.454 \\
ACE inhibitors & $13(21.7 \%)$ & $20(32.8 \%)$ & 0.17 \\
Beta blockers & $9(15 \%)$ & $18(29.5 \%)$ & 0.055 \\
Ca + channel blockers & $10(16.7 \%)$ & $7(11.5 \%)$ & 0.411 \\
Alpha agonist & $2(3.3 \%)$ & $3(4.9 \%)$ & 0.661 \\
Nitrates & $4(6.7 \%)$ & $5(8.3 \%)$ & 0.748 \\
Aspirin & $23(37.7 \%)$ & $33(54.1 \%)$ & 0.082 \\
Steroids & $12(20 \%)$ & $15(24.6 \%)$ & 0.544 \\
NSAIDS & $10(16.7 \%)$ & $15(24.6 \%)$ & 0.282 \\
\hline ACE
\end{tabular}

ACE inhibitors $=$ Angiotensin Converting Enzyme Inhibitors, NSAIDs $=$ Nonsteroidal anti-inflammatory drugs

Table 3. Peri-operative relevant details of the study subjects grouped according to hsCRP level $<$ or $>3 \mathrm{mg} / \mathrm{dl}$

\begin{tabular}{llll}
\hline & HsCRP <3mg./dl $(\mathbf{n}=60)$ & HsCRP $>3 \mathbf{m g} . / \mathbf{d l}$ (n=61) & p-value \\
\hline Types of anesthesia & & & 0.173 \\
General (GA) & $30(50 \%)$ & $23(37.7 \%)$ & $\mathrm{df}=1$ \\
Regional & $30(50 \%)$ & $38(62.3 \%)$ & 0.0001 \\
Operative time (mins) & $88.5(+7.2)$ & $107.3(+9.01)$ & 0.058 \\
Core temperature(oC) & $38.0(+1.2)$ & $38.4(+1.11)$ & 0.226 \\
Hemoglobin $<10 \mathrm{mg} \%$ & $36(60 \%)$ & $43(70.5 \%)$ & \\
\hline
\end{tabular}

Table 4. Comparison of post operative morbidity on D-7among study subjects grouped according to hsCRP level $<$ or $>3 \mathrm{mg} / \mathrm{dl}$

\begin{tabular}{lcrc}
\hline & hsCRP $<3 \mathbf{m g . / d l}(\mathbf{n}=\mathbf{6 0})$ & hsCRP $>$ 3mg./dl (n=61) & p-value \\
\hline With complication & $27(45 \%)$ & $31(50.9 \%)$ & 0.522 \\
Gl disorders & $16(26.7 \%)$ & $18(29.5 \%)$ & 0.726 \\
Infection & $8(13.3 \%)$ & $12(19.7 \%)$ & 0.348 \\
Cardiac disorders & $7(11.7 \%)$ & $9(14.8 \%)$ & 0.616 \\
Wound dehiscence & $2(3.3 \%)$ & $4(6.6 \%)$ & 0.414 \\
\hline
\end{tabular}

Table 5. Comparison of post operative morbidity on D-14 among study subjects grouped according to hsCRP level $<$ or $>3 \mathrm{mg} / \mathrm{dl}$

\begin{tabular}{|c|c|c|c|}
\hline & hsCRP $<3 \mathrm{mg} . / \mathrm{dl}(\mathrm{n}=60)$ & hsCRP > 3mg./dl $(n=61)$ & p-value \\
\hline With complication & $2(3.3 \%)$ & $10(16.4 \%)$ & \multirow{4}{*}{0.022} \\
\hline GI disorders & $2(3.3 \%)$ & $3(4.9 \%)$ & \\
\hline Infection & $2(3.3 \%)$ & $7(11.5 \%)$ & \\
\hline Cardiac disorders & $1(1.7 \%)$ & $2(3.3 \%)$ & \\
\hline
\end{tabular}


The main pillar of the study is the fact that the patients, investigators and healthcare personnel were blinded to the key data i.e. hsCRP. So, it is unlikely that clinical assessment by the investigators were anyway biased to diagnose post operative morbidity in the study subjects. As peri/post operative morbidity is always an unacceptable outcome for surgical procedures, measuring and manipulating certain parameters pre and peri operatively may reduce/predict the adverse events and finally benefit the quality of patient care in the hospital.

There is lack of significant differences in post operative complications in both the groups on the seventh postoperative day. This may be due to the fact that only qualitative reflection of various complications has been made and we have not recorded the degree of severity of these complications. All of the complications are not directly related to cardiovascular dysfunction (and hence hsCRP) but the commonest complication is gastro-intestinal side effects for which peri-operative gut hypo perfusion is at least partially responsible. ${ }^{19}$ In contrast, both the incidence of complications 10/12 $(\mathrm{P}<0.05)$ and prolonged hospital stay was observed in the higher hsCRP group on the fourteenth day.

\section{CONCLUSIONS}

Baseline hsCRP demographics may prove to be a useful tool in different surgical populations because the underlying pathology requiring surgery may be an important determinant of preoperative hsCRP levels. We can assume that surgical complications may not be due to the magnitude and complexity of surgical interventions alone but also monitored by underlying chronic inflammatory process. The data obtained by this study suggests that hsCRP merits further study in the perioperative setting for specific surgical groups. Preoperative measurement of hsCRP may be a fruitful strategy to stratify perioperative care.

\section{REFERENCES}

1. Ridker PM. High-sensitivity C-reactive protein: potential adjunct for global risk assessment in the primary prevention of cardiovascular disease. Circulation. 2001 Apr 3;103(13):1813-8.

2. Tsimikas S, Willerson JT, Ridker PM.C-reactive protein and other emerging blood biomarkers to optimize risk stratification of vulnerable patients. J Am Coll Cardiol. 2006 Apr 18;47(8 Suppl):C19-31.

3. Church TS, Barlow CE, Earnest CP, Kampert JB, Priest EL, Blair SN. Associations between cardiorespiratory fitness and C-reactive protein in men. Arterioscler Thromb Vasc Biol. 2002 Nov 1;22(11):1869-76.

4. Kullo IJ, Khaleghi M, Hensrud DD. Markers of inflammation are inversely associated with $\mathrm{VO} 2$ max in asymptomatic men. J Appl Physiol. 2007 Apr;102(4):1374-9. Epub 2006 Dec 14.

5. Older P, Hall A, Hader R. Cardiopulmonary exercise testing as a screening test for perioperative management of major surgery in the elderly. Chest. 1999;116:355-62.

6. CDC/AHA Workshop on Markers of Inflammation and Cardiovascular Disease. Application to Clinical and Public Health Practice. Circulation. 2004;110:543-78.

7. Eagle KA, Berger PD, Calkins H, et al. ACC/AHA Guideline update foR Perioperative cardiovascular evaluation for non cardiac surgery executive summary Anaesthesia and Analgesia. 2002;94:1052-64

8. Shapiro M, Munoz A, Tager IB et al. Risk factors for infection at the operative site after abdominal or vaginal hysterectomy. New England Journal of Medicine. 1982;307:1661-6.

9. Bennett-Guerrero E, Feierman DE, Barclay GR, et al. Preoperative and intra-operative predictors of postoperative morbidity, poor graft function, and early rejection in 90 patients undergoing liver transplantation. Archives of surgery. 2001;136:1177-83.

10. Hogue CW Jr, Goodnough LT, Monk TG. Perioperative myocardial episodes are related to haematocrit level in patients undergoing radical prostatectomy. Transfusion. 1998; 38: 924- 3.

11. Frank SM, Fleisher LA, Breslow MJ, et al. Perioperative maintenance of normothermia reduces the incidence of morbid cardiac events. A randomized clinical trial. J Am Med Assoc. 1997;277:1127-34

12. Bennett-Guerrero E, Welsby I, Dunn TJ, et al. The use of a postoperative morbidity survey to evaluate patients with prolonged hospitalization after routine, moderate risk, elective surgery. Anaesthesia and Analgesia. 1999;89:514-9.

13. Gockel I, Dirksen K, Messow CM, Junginger T. Significance of pre operative C-reactive protein as a parameter of peri operative course and long term prognosis in squamous cell carcinoma and adenocarcinoma of oesophagus. World Journal of Gastroenterology. 2006;12:3746-50.

14. Owens CD, Ridker PM, Belkin M, et al. Elevated C reactive protein levels are associated with post operative events in patients undergoing lower extremity vein bypass surgery. Journal of Vascular surgery. 2007;45:229

15. Maenpaa H, Laiho K, Kauppi M, et al. A comparison of C-reactive protein changes in primary and revision hip arthroplasty in patients with rheumatoid arthritis. Journal of Arthroplasty. 2002;17:108-10.

16. Smeeth L, Thomas SL, Hall AJ, et al. Risk of myocardial infarction and stroke after acute infection or vaccination. New England Journal of Medicine. 2004;351:2611-8.

17. Del Rincon ID, Williams K, Stern MP et al. High incidence of cardiovascular events in a rheumatoid arthritis cohort not explained by traditional risk factors. Arthritis Rheumatology. 2001;44:2737-45.

18. Gan TJ, Soppitt A, Maroof M, et al. Goal directed intraoperative fluid administration reduces length of hospital stay after major surgery. Anaesthesiology. 2002;97:820-6.

19. Mythen MC. Postoperative gastrointestinal tract dysfunction. Anaesthesia and Analgesia. 2005;100:196-204. 